\title{
Arterial Oxygenation Determines Autoregulation of Cerebral Blood Flow in the Fetal Lamb
}

\author{
W. A. TWEED, ${ }^{(22)}$ J. COTE, M. PASH, AND H. LOU \\ Department of Anesthesia, University of Manitoba, Winnipeg, Manitoba, Canada
}

\begin{abstract}
Summary
We examined autoregulation of cerebral blood flow (CBF) over the range of oxygen tension commonly observed in the chronic fetal lamb preparation. Seventeen animals were surgically prepared under general anesthesia for chronic in utero studies. Based on measured resting arterial $\mathrm{PO}_{2}$ and calculated \% saturation 24$48 \mathrm{~h}$ after surgery, two groups were defined: a normoxic group of eight with saturation of $57 \%$ or higher (our laboratory normal for physiologically stable preparations) and an hypoxic group of nine with saturation less than $57 \%$. Regional $\mathrm{CBF}$ was measured with radiolabeled $15-\mu \mathrm{m}$ microspheres. Autoregulation of $\mathrm{CBF}$ was assessed by measuring the change in CBF when fetal mean arterial blood pressure (MABP) was acutely decreased and increased by withdrawal and reinfusion of fetal blood. In normoxic animals CBF was constant over an MABP range of 42-61 torr in all four areas of the brain examined: cerebral hemispheres, basal ganglia, cerebellum, and brain stem. In hypoxic animals CBF was pressure dependent in all areas over an MABP range of 46-73 torr, i.e., autoregulation was abolished. These studies demonstrate that the mechanism of autoregulation is functionally developed in the mature fetal lamb, but operationally dependent upon arterial oxygen concentration. Below a saturation of approximately 50$60 \% \mathrm{CBF}$ varies directly with perfusion pressure.
\end{abstract}

Abbreviations

BP, blood pressure

CBF, cerebral blood flow

cpm, count per min

i.d., internal diameter

MABP, mean arterial blood pressure

rCBF, regional cerebral blood flow

Impairment of cerebrovascular autoregulation is now generally believed to be an important pathophysiologic mechanism in the genesis of hypoxic and hemorrhagic brain injury of the newborn $(10,20)$. The theoretical model states that with impairment of autoregulation the cerebral microcirculation is rendered vulnerable to changes in arterial blood pressure. Systemic hypotension results in ischemic cerebral blood flow (CBF) and cerebral infarction, whereas hypertension leads to cerebral hyperemia, rupture of poorly supported capillaries in the vulnerable subependymal germinal matrix, and cerebral hemorrhage $(10,15)$.

Impaired autoregulation has been demonstrated in the severely asphyxiated fetal lamb (12) and in sick human newborns (11). The well oxygenated newborn lamp has been shown to autoregulate (16), and there is evidence that the normoxic fetal lamb has at least partial autoregulatory control of $\mathrm{CBF}$ (19). But the functional maturity of the autoregulatory mechanism in the fetal lamb, and its sensitivity to hypoxia, have not been clearly established.

The present studies were designed to examine autoregulation in utero in the near term fetal lamb, and to determine its stability over the range of arterial oxygen tension normally encountered in chronically prepared laboratory animals.

\section{MATERIALS AND METHODS}

We studied 17 near term fetal lambs estimated to be $130-140$ days gestation. Our methods for fetal studies in the chronically prepared sheep have been described in previous publications (12, 19). Surgical preparation was done under halothane/oxygen general anesthesia with controlled ventilation via an endotracheal tube. The ewe was placed in the supine position and femoral arterial and venous catheters inserted. Through a midline abdominal approach a small hysterotomy was made to expose the fetal limbs. A hind limb was delivered and femoral arterial and venous catheters $(0.86 \mathrm{~mm}$ i.d.) were advanced to the decending aorta and inferior vena cava. A forelimb was then delivered and an axillary artery catheter advanced to the common brachio-cephalic-trunk. The incisions were closed and all catheters were brought subcutaneously to a pocket on the ewe's flank. Prophylactic antibiotics (penicillin and gentamycin) were administered to both mother and fetus.

Studies were performed $24-48 \mathrm{~h}$ after surgical preparation. In the laboratory the ewe stood quietly in a cart and was allowed hay and water ad libitum. Fetal and maternal arterial blood pressures and fetal venous pressures were continuously recorded with Stratham P23 pressure transducers and an Hewlett Packard dynograph. Maternal femoral and fetal ascending aortic blood gases were measured with a Corning 165 blood gas analyzer at $37^{\circ} \mathrm{C}$. Maternal rectal temperature was monitored and averaged $38.5^{\circ} \mathrm{C}$.

Percent fetal oxygen saturation was calculated using the equation of Meschia et al. (13):

$$
\log \mathrm{Po}_{2}=\log \left(\mathrm{Po}_{2}\right) 50,7.4-\mathrm{K}_{2}(\mathrm{pH}-7.4)+0.368 \log \frac{\mathrm{S}}{100-\mathrm{S}}
$$

in which $\left(\mathrm{Po}_{2}\right)$ 50,7.4 is the oxygen tension at which the hemoglobin is half saturated at $\mathrm{pH}$ of $7.4, \mathrm{~K}_{2}$ and 0.368 are two coefficients and $\mathrm{S}$ is the \% saturation of hemoglobin with oxygen. The average values of $\mathrm{K}_{2}$ and $\log \left(\mathrm{PO}_{2}\right) 50,7.4$ for fetal hemoglobin in the lamb are 0.532 and 1.213 , respectively.

Fetal regional brain blood flow was measured by the radioactive microsphere technique, using $15-\mu \mathrm{m}$ diameter microspheres labeled with gamma emitting $\left[{ }^{141} \mathrm{Ce}\right],\left[{ }^{51} \mathrm{Cr}\right]$, or $\left[{ }^{85} \mathrm{Sr}\right]$ (3M Company). For each measurement approximately 1 million spheres were injected into the inferior vena cava over $30 \mathrm{sec}$. Arterial blood samples were withdrawn at a fixed rate, $1.94 \mathrm{ml} / \mathrm{min}$., from the brachiocephalic catheters during and for $1.5 \mathrm{~min}$ after microsphere injection.

After the ewe had rested quietly in the laboratory for $1-2 \mathrm{~h}$ a complete set of control measurements were made. Fetal hypotension was then produced by withdrawal of fetal arterial blood. Sixty to $150 \mathrm{ml}$ of blood (average 92.8 ) were withdrawn over $5-10$ min to reduce MABP by approximately $20 \%$. After stabilization for 5-15 min under hypotensive conditions a complete second set of measurements was made. The heparinized blood was then reinfused and within 15 min a third set of measurements were made.

At the end of the experiment the ewe and fetus were painlessly 
killed with intravenous sodium pentothal and saturated $\mathrm{KCl}$ solution. The fetus was autopsied to validate catheter placement, and the brain was removed. Tissue samples from both sides were cut, weighed, and packed in counting tubes. The samples included all of the brain stem, and deep cerebral tissue, and about $50 \%$ of the cerebral hemisphere of each side. Gamma counts of each label in the weighed tissue samples and in the arterial blood samples were measured by a Searle gamma well counter.

If microspheres are homogenously distributed in the arterial blood supplying an organ, and are completely removed from blood during passage through the organ, then the following equation calculates organ blood flow (4):

$$
\mathrm{F}=\mathrm{Fa} \times \frac{\mathrm{i} \text { organ }}{\mathrm{i} \text { arterial }}
$$

$\mathrm{F}$, organ blood flow $(\mathrm{ml} / 100 \mathrm{~g} / \mathrm{min}) ; \mathrm{Fa}$, withdrawal rate of the reference arterial blood sample; i organ, microsphere content of the organ tissue (cpm/100 g); and i arterial, microsphere content of the total reference arterial blood sample (cpm).

The data was analyzed as paired measurements, with statistical comparison by the student $t$ test for paired data.

\section{RESULTS}

Seventeen near term fetal lambs were studied. Arterial oxygen tension in blood from the ascending aorta was measured in the resting state $24-48 \mathrm{~h}$ after surgical preparation. The range of observed values for $\mathrm{Po}_{2}$ was 12.0-22.0 torr, and for calculated arterial oxygen saturation, 29.5-68.7\%. The average $\mathrm{Po}_{2}$ and $\mathrm{O}_{2}$ saturation for chronically prepared physiologically stable animals in our laboratory is 19 and $57 \%$. Using an arterial $\mathrm{O}_{2}$ saturation of $57 \%$ as the arbitrary dividing point we have defined two groups for comparative purposes: eight animals with an $\mathrm{O}_{2}$ saturation of $57 \%$ or higher are termed the normoxic group and nine animals with less than $57 \% \mathrm{O}_{2}$ saturation are termed the hypoxic group (Table 1). Except for $\mathrm{PO}_{2}$ and $\mathrm{O}_{2}$ saturation there were no major differences in control state measurements between these groups. Although the arterial $\mathrm{pH}$ of the hypoxic group was slightly lower it was well within the normal range.

Table 2 and Figure 1 present the data for the normoxic group during decreasing and increasing blood pressure (BP). Eight animals were subjected to hypotension by blood withdrawal with a mean decrease of $26 \%$ in arterial BP. In six animals a mean increase in $\mathrm{BP}$ of $41 \%$ was then produced by reinfusion of withdrawn blood. Regional cerebral blood flow (rCBF) measurements before and after blood withdrawal and before and after reinfusion were compared. Although BP changes were pronounced (26\% and $41 \%$ ) there were no changes in $\mathrm{rCBF}$ in any region of the brain.
Arterial oxygenation did not change although $\mathrm{PCO}_{2}$ increased significantly and $\mathrm{pH}$ fell during hypotension. We ascribe this respiratory acidosis to impairment of placental $\mathrm{CO}_{2}$ exchange as a result of decreased fetal placental perfusion $(18,19)$.

In Table 3 and Figure 1 the data for the hypoxic group during decreasing and increasing BP is presented. Eight animals were made hypotensive by blood withdrawal with a mean decrease of $31 \%$ in arterial BP. In seven animals BP was increased by reinfusion of withdrawn blood, with a mean increase in BP of $39 \%$. These are very similar to the BP changes in the normoxic group. Again rCBF measurements before and after blood withdrawal and before and after reinfusion were compared. All regions of the brain showed a pressure dependent $\mathrm{rCBF}$, regional perfusion significantly decreasing with hypotension and increasing with hypertension. Not only did the mean values for $\mathrm{rCBF}$ change significantly, but every animal in this group demonstrated impaired autoregulation with changing $\mathrm{BP}$. The magnitude of the changes in $\mathrm{PCO}_{2}$ and $\mathrm{pH}$ was similar to the normoxic group.

\section{DISCUSSION}

These studies indicate that the mechanism of autoregulation is functionally mature in the near term fetal lamb, and can be demonstrated to be operationally intact in chronically prepared,

Table 1. Comparison of control state measurements of normoxic and hypoxic groups ${ }^{1}$

\begin{tabular}{lcccc}
\hline \multicolumn{1}{c}{ Variable } & $\begin{array}{c}\text { Normoxic } \\
\text { group (8) }\end{array}$ & $\begin{array}{c}\text { Hypoxic } \\
\text { group (9) }\end{array}$ & Difference & $p$ value \\
\hline $\begin{array}{l}\mathrm{rCBF}\left(\mathrm{ml} \cdot \mathrm{g}^{-1} \cdot \mathrm{min}^{-1}\right) \\
\mathrm{Brain} \mathrm{stem}\end{array}$ & $1.92 \pm 0.19$ & $1.78 \pm 0.24$ & & $\mathrm{NS}$ \\
rCBF & & & & $\mathrm{NS}$ \\
$\begin{array}{l}\text { Cerebellum } \\
\text { rCBF }\end{array}$ & $1.55 \pm 0.17$ & $1.60 \pm 0.19$ & & \\
$\begin{array}{l}\text { Basal ganglia } \\
\text { rCBF }\end{array}$ & $1.76 \pm 0.27$ & $1.77 \pm 0.24$ & & $\mathrm{NS}$ \\
$\begin{array}{l}\text { Cerebral hemi- } \\
\text { spheres }\end{array}$ & $1.00 \pm 0.11$ & $1.13 \pm 0.14$ & & $\mathrm{NS}$ \\
$\mathrm{MABP}_{\text {(torr) }}$ & $54.6 \pm 3.0$ & $56.6 \pm 2.4$ & & $\mathrm{NS}$ \\
$\mathrm{PaO}_{2}$ (torr) & $19.8 \pm 0.5$ & $15.9 \pm 0.7$ & 3.9 & $<0.001$ \\
$\mathrm{O}_{2}$ Saturation (\%) & $63.3 \pm 1.5$ & $45.7 \pm 2.9$ & 17.6 & $<0.001$ \\
$\mathrm{PaCO}_{2}$ (torr) & $37.8 \pm 0.9$ & $38.0 \pm 1.4$ & & $\mathrm{NS}$ \\
$\mathrm{pH}$ & $7.41 \pm 0.01$ & $7.37 \pm 0.01$ & & $<0.02$ \\
\hline
\end{tabular}

${ }^{1} \mathrm{rCBF}$ is regional cerebral blood flow, MABP is mean arterial blood pressure. All blood gas values are for ascending aortic blood, proximal to the ductus arteriosis. Statistical comparison by the $t$ test for unpaired samples. All values are expressed as mean \pm S.D.M.

Table 2. Autoregulation of fetal $r C B F$ in normoxia ${ }^{1}$

\begin{tabular}{|c|c|c|c|c|c|c|c|c|}
\hline \multirow{2}{*}{ Variable } & \multicolumn{4}{|c|}{ Decreasing blood pressure ( 8 ) } & \multicolumn{4}{|c|}{ Increasing blood pressure (6) } \\
\hline & Control & Hypotension & Change $(\%)$ & $P$ value & Control & Hypertension & Change (\%) & $P$ value \\
\hline \multicolumn{9}{|l|}{$\mathrm{rCBF}\left(\mathrm{ml} \cdot \mathrm{g}^{-1} \cdot \mathrm{min}^{-1}\right)$} \\
\hline $\begin{array}{l}\text { Brain stem } \\
\text { rCBF }\end{array}$ & $1.89 \pm 0.19$ & $1.90 \pm 0.24$ & +1 & NS & $1.69 \pm 0.25$ & $1.76 \pm 0.15$ & +4 & NS \\
\hline $\begin{array}{l}\text { Cerebellum } \\
\text { rCBF }\end{array}$ & $1.57 \pm 0.16$ & $1.43 \pm 0.20$ & -9 & NS & $1.20 \pm 0.15$ & $1.38 \pm 0.17$ & +15 & NS \\
\hline $\begin{array}{l}\text { Basal ganglia } \\
\text { rCBF }\end{array}$ & $1.70 \pm 0.27$ & $1.65 \pm 0.25$ & -3 & NS & $1.55 \pm 0.23$ & $1.68 \pm 0.24$ & +8 & NS \\
\hline Cerebral hemispheres & $1.03 \pm 0.10$ & $0.98 \pm 0.13$ & -5 & NS & $0.88 \pm 0.13$ & $0.98 \pm 0.10$ & +11 & NS \\
\hline MABP (torr) & $56.6 \pm 3.7$ & $41.8 \pm 2.8$ & -26 & $<0.001$ & $43.5 \pm 4.5$ & $61.3 \pm 5.7$ & +41 & $<0.001$ \\
\hline $\mathrm{PaO}_{2}$ (torr) & $19.7 \pm 0.5$ & $20.8 \pm 0.8$ & & NS & $20.8 \pm 0.8$ & $19.6 \pm 0.5$ & & NS \\
\hline $\mathrm{O}_{2}$ Saturation (\%) & $62.9 \pm 1.6$ & $63.5 \pm 2.1$ & & NS & $63.8 \pm 2.0$ & $59.3 \pm 1.8$ & & NS \\
\hline $\mathrm{PaCO}_{2}$ (torr) & $37.3 \pm 1.0$ & $41.1 \pm 1.4$ & +3.8 & $<0.02$ & $42.0 \pm 1.6$ & $41.8 \pm 1.8$ & & NS \\
\hline $\mathrm{pH}$ & $7.41 \pm 1.0$ & $7.38 \pm .01$ & -0.03 & $<0.02$ & $7.38 \pm 0.01$ & $7.37 \pm 0.02$ & & NS \\
\hline
\end{tabular}

${ }^{1}$ Abbreviations as for Table 1. Statistical comparison by the $t$ test for paired samples. Paired measurements of all variables were compared before and after blood withdrawal and before and after reinfusion. In most cases, the measurements made during hypotension served as the controls for the measurements made during hypertension. All values are expressed as mean \pm S.D.M. 


\section{AUTOREGULATION OF FETAL CBF IN: NORMOXIA HYPOXIA}
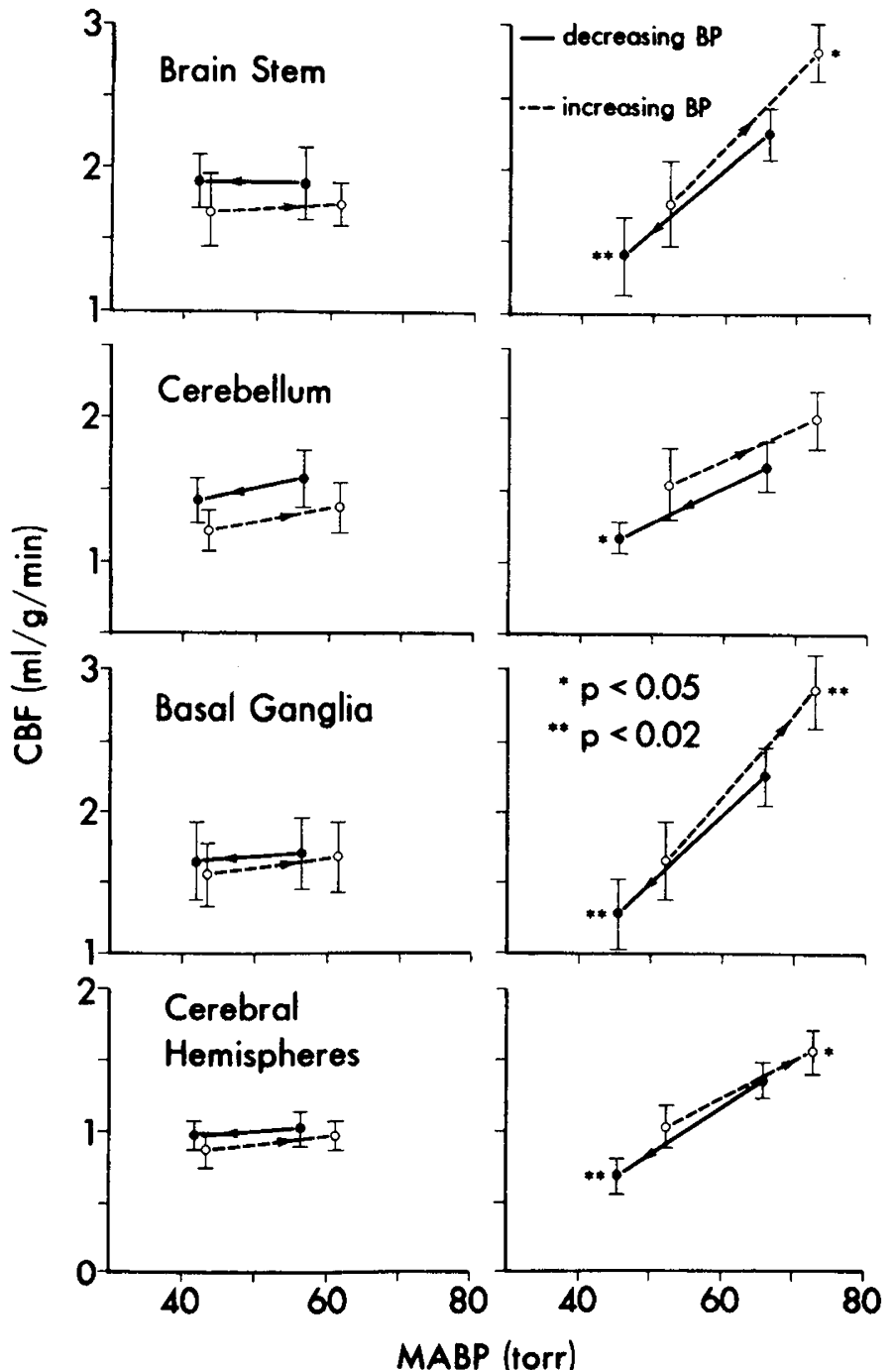

Fig. 1. Autoregulation of fetal regional cerebral blood flow in normoxia and hypoxia. The vertical bars represent the standard deviations of the means. The direction of the arrows indicates decreasing blood pressure (BP) or increasing BP. Thus solid lines are decreasing BP, hatched lines increasing BP. Abbreviations are as in Table 1. physiologically stable, and well oxygenated animals. It appears, however, that autoregulation is operationally very dependent upon arterial oxygen concentration and, in these experiments, was consistently abolished when arterial oxygen saturation was below approximately $57 \%$. Because fetal hemoglobin in our animals averages $11.5 \mathrm{~g} / \mathrm{dl}$ this corresponds to an arterial $\mathrm{O}_{2}$ content of 8 $9 \mathrm{ml} / \mathrm{dl}$ or 3-4 millimoles. This is above the level of oxygenation at which hypoxic hyperemia is observed $(1,6)$. Jones et al. (8) have demonstrated that $\mathrm{CBF}$ in the lamb is a function of arterial oxygen concentration over a wide concentration range. In the fetal animal they observed a hyperbolic relationship between $\mathrm{CBF}$ and arterial $\mathrm{O}_{2}$ content when $\mathrm{O}_{2}$ content was $\simeq 3 \mathrm{mM}$ (7); thus, only lower arterial levels of $\mathrm{O}_{2}$ have an important influence on fetal CBF. It appears that autoregulation in the fetus is abolished at a level of oxygenation a little higher than that required to demonstrate hypoxic hyperemia.

The threshold of hemoglobin $\mathrm{O}_{2}$ saturation for impairment of autoregulation in the fetus, $50-60 \%$, is also very similar to that which abolishes autoregulation in adult dogs (3).

Although impairment of autoregulation was evident, these experiments do not provide any indication of the time relationships involved. That is, they do not tell us whether autoregulation is functionally oxygen dependent with immediate recovery upon restoration of normoxia or whether hypoxia temporarily disrupts the mechanism of autoregulation with a time delay to restoration of normal function. Previous work from our laboratory suggests that the latter may be the case (2).

In 1969 Purves and James (16) observed autoregulation of CBF in the fetal and newborn lamb. They studied acutely exteriorized fetal lambs with normal arterial blood gases (mean $\mathrm{Po}_{2}, 23-24$ torr and mean $\mathrm{PCO}_{2} 40$ torr) and found that grey matter blood flow was independent of MABP over the range 43-90 torr for exteriorized fetuses and 45-93 torr for newborn lambs. Although they attempted to assess autoregulation with elevated $\mathrm{PCO}_{2}$, they did not look at the effect of reduced oxygen tension. Toubas el al. (18) also observed that $\mathrm{CBF}$ was maintained during hemorrhagic hypotension in the well oxygenated fetal lamb.

The newborn dog (5) and piglet (9), which have immature brains at birth, were also observed to autoregulate between MABPs of 27-97 torr and 50-105 torr, respectively. Although normal autoregulation has not yet been demonstrated in the human newborn, it has been observed in young animals with both mature and immature brains at birth.

In a previously published study (19) we reported that the physiologically stable fetal lamb showed evidence of CBF autoregulation to $\mathrm{BP}$ changes of $\pm 20 \%$. But autoregulation to hypotension was incomplete, probably because arterial oxygen concentration in some of those animals fell near the threshold for impairment. When normoxia is more rigidly defined and normo-

Table 3. Impaired autoregulation of fetal $r C B F$ in hypoxia ${ }^{1}$

\begin{tabular}{|c|c|c|c|c|c|c|c|c|}
\hline \multirow{2}{*}{ Variable } & \multicolumn{4}{|c|}{ Decreasing blood pressure $(8)$} & \multicolumn{4}{|c|}{ Increasing blood pressure (7) } \\
\hline & Control & Hypotension & Change (\%) & $P$ value & Control & Hypertension & Change (\%) & $P$ value \\
\hline \multicolumn{9}{|l|}{$\mathrm{rCBF}\left(\mathrm{ml} \cdot \mathrm{g}^{-1} \cdot \mathrm{min}^{-1}\right)$} \\
\hline $\begin{array}{l}\text { Brain stem } \\
\text { rCBF }\end{array}$ & $2.27 \pm 0.28$ & $1.41 \pm 0.19$ & -38 & $<0.02$ & $1.77 \pm 0.31$ & $2.85 \pm 0.21$ & +61 & 0.05 \\
\hline $\begin{array}{l}\text { Cerebellum } \\
\text { rCBF }\end{array}$ & $1.69 \pm 0.11$ & $1.18 \pm 0.18$ & -30 & $<0.02$ & $1.55 \pm 0.25$ & $2.05 \pm 0.20$ & +32 & NS \\
\hline $\begin{array}{l}\text { Basal ganglia } \\
\text { rCBF }\end{array}$ & $2.26 \pm 0.26$ & $1.28 \pm 0.20$ & -43 & $<0.01$ & $1.65 \pm 0.29$ & $2.85 \pm 0.26$ & +73 & $<0.02$ \\
\hline Cerebral hemispheres & $1.36 \pm 0.12$ & $0.80 \pm 0.13$ & -41 & $<0.001$ & $1.02 \pm 0.16$ & $1.56 \pm 0.15$ & +53 & $<0.05$ \\
\hline $\mathrm{MABP}$ (torr) & $66.3 \pm 4.5$ & $45.8 \pm 3.2$ & -31 & $<0.01$ & $52.3 \pm 3.8$ & $72.9 \pm 5.3$ & +39 & $<0.001$ \\
\hline $\mathrm{PaO}_{2}$ (torr) & $16.0 \pm 0.6$ & $20.1 \pm 1.3$ & +4.1 & $<0.02$ & $16.4 \pm 1.0$ & $15.0 \pm 0.8$ & & NS \\
\hline $\mathrm{O}_{2}$ Saturation (\%) & $44.5 \pm 3.0$ & $51.4 \pm 4.2$ & & NS & $45.3 \pm 3.2$ & $38.6 \pm 4.8$ & & NS \\
\hline $\mathrm{PaCO}_{2}$ (torr) & $38.2 \pm 2.0$ & $42.0 \pm 2.3$ & +3.8 & NS & $38.7 \pm 1.3$ & $41.9 \pm 2.7$ & & NS \\
\hline $\mathrm{pH}$ & $7.36 \pm 0.01$ & $7.28 \pm 0.03$ & -0.08 & $<0.05$ & $7.35 \pm 0.04$ & $7.33 \pm 0.03$ & & NS \\
\hline
\end{tabular}

'Abbreviations as for Table 1. Statistical comparison by the $t$ test for paired samples. Paired measurements of all variables were compared before and after blood withdrawal and before and after reinfusion. In most cases, the measurements made during hypotension served as the controls for the measurements made during hypertension. All values are expressed as mean \pm S.D.M. 
capnia prevails, as in the present study, no difference is seen in autoregulation to decreased or increased BP within the range of 40-70 torr.

Although in our animals $\mathrm{PCO}_{2}$ increased during hypotension, probably as a result of decreased fetal placental perfusion, the increase was the same in normoxic and hypoxic animals and therefore could not account for the observed differences in rCBF response. During hypertension $\mathrm{PCO}_{2}$ was unchanged in normoxic animals but rose by an average of 3.2 torr in the hypoxic group. The $\mathrm{CO}_{2}$ responsiveness of $\mathrm{CBF}$ in fetal animals has been measured (16). This may explain why the \% increase in $\mathrm{rCBF}$ in the hypoxic group was out of proportion compared to the $\%$ increase in MABP.

Impaired autoregulation of $\mathrm{CBF}$ in sick newborn infants has been inferred by the studies of Lou et al. (11) and Milligan (14). They correlated measurements of CBF and MABP in stressed infants and concluded that $\mathrm{CBF}$ was pressure dependent. It can be reasonably assumed, therefore, that the observations we have made in fetal lambs may have some relevance to the human newborn. Because the type of controlled experiment possible with an animal model is impossible to reproduce in a clinical setting, validation of this assumption will be difficult; however if a theoretical model, based on animal experimentation, is utilized to guide clinical management, the applicability of the model can at least be tested (10).

These studies indicate that autoregulation of $\mathrm{CBF}$ in the fetal lamb is intact under ideal physiologic conditions, but is abolished during moderate hypoxia. Because the degree of hypoxia corresponds to that observed during mild stress or even normal delivery (17) we can predict that $\mathrm{CBF}$ is likely to be pressure passive in most newborns.

\section{REFERENCES AND NOTES}

1. Ashwal, S., Majcher, J. S., and Longo, L. L.: Patterns of fetal lamb regional cerebral blood flow during and after prolonged hypoxia: studies during the post-hypoxic recovery period. Amer. J. Obs. Gynecol., 139: 365 (1981)

2. Cote, J., Tweed, W. A., Lou, H., Gregory, G., and Wade, J. G.: Impairment and recovery of autoregulation of cerebral blood flow in the newborn lamb. (Submitted to Pediatric Research).

3. Haggendal, E. and Johansson, B.: Effects of arterial carbon dioxide tension and oxygen saturation on CBF autoregulation in dogs. Acta Physiol. Scand., Suppl. 258: 27 (1965)
4. Hales, J. R. S.: Radioactive microsphere techniques for studies of the circulation. Clin. Exp. Pharmacol. Physiol. (Suppl.), 1: 31 (1974).

5. Hernandez, M. J., Brennan, R. W., and Bowman, G. S.: Autoregulation of cerebral blood flow in the newborn dog. Brain Res., 184: 199 (1980).

6. Johnson, G. N., Palahniuk, R. J., Tweed, W. A., Jones, M. V., and Wade, J. G. Regional cerebral blood flow changes during severe fetal asphyxia produced by slow partial umbilical cord compression. Amer. J. Obs. Gynecol., 135: 48 (1979).

7. Jones, D. M., Sheldon, R. E., Peeters, L. L., Makowski, E. L., and Meschia, G.: Regulation of cerebral blood flow in the ovine fetus. Amer. J. Physiol., 235: H162 (1978).

8. Jones, D. M., Traystman, R. J., Simmons, M. A., and Molteni, R. A.: Effects of changes in arterial oxygen content on cerebral blood flow in the lamb. Amer. J. Physiol., 240: H209 (1981).

9. Laptook, A., Stonestreet, B. S., and Oh, W.: Autoregulation of brain blood flow in the newborn piglet: regional differences in flow reduction during hypotension. Early Human Development, 6: 99 (1982).

10. Lou, H. C.: Perinatal hypoxic-ischemic brain damage and intraventricular hemorrhage. A pathogenetic model. Arch. Neurol., 37: 585 (1980).

11. Lou, H. C., Lassen, N. A., and Friis-Hansen, B.: Impaired autoregulation of cerebral blood flow in the distressed newborn infant. J. Pediatr., 94: 118 (1979).

12. Lou, H. C., Lassen, N. A., Tweed, W. A., Johnson, G., Jones, M., and Palahniuk, R. J.: Pressure passive cerebral blood flow and breakdown of the blood-brain barrier in experimental fetal asphyxia. Acta Paediatrica Scand., 68: 57 (1979).

13. Meschia, G., Cotter, J. R., Breathnach, C. S., and Barron, D. H.: The diffusability of oxygen across the sheep placenta. Quart. J. of Exp. Physiol., 50: 466 (1965).

14. Milligan, D. W. A.: Failure of autoregulation and intraventricular hemorrhage in preterm infants. Lancet, $1: 896$ (1980).

15. Pape, K. E. and Wigglesworth, J. S.: Haemorrhage, ischemia and the perinatal brain pp. 133-146. (J. B. Lippincott, Philadelphia, 1979)

16. Purves, M. J. and James, I. M.: Observations on the control of cerebral blood flow in the sheep fetus and newborn lamb. Circ. Res., 25: 651 (1969)

17. Saling, E.: Fetal and neonatal hypoxia in relation to clinical obstetric practise. pp. 29-38 (Edward Arnold, Publishers Ltd., London, 1968).

18. Toubas, P. L., Silverman, N. H., Heymann, M. A., and Rudolph, A. M. Cardiovascular effects of acute hemorrhage in fetal lambs. Amer. J. Physiol., H45 (1981).

19. Tweed, W. A., Cote, J., Wade, J. G., Gregory, G., and Mills, A.: Preservation of fetal brain blood flow relative to other organs during hypovolemic hypotension. Pediatr. Res., 16: 137 (1982).

20. Volpe, J. J.: Current concepts in neonatal medicine: Neonatal Intraventricular hemorrhage. N. Engl. J. Med., 304: 886 (1981)

21. The authors wish to acknowledge with thanks the financial support of the Medical Research Council of Canada, and the Manitoba Heart Foundation; and the technical help of Mr. Wayne Pucci and Miss Maureen Cumming.

22. Requests for reprints should be addressed to: Dr. W. A. Tweed, Department of Anesthesia, Health Sciences Center-General, 700 William Avenue, Winnipeg, Manitoba, Canada, R3E 0Z3.

23. Received for publication January 8, 1982

24. Accepted for publication August 12, 1982. 